\title{
CURRÍCULO, RELAÇÕES DE GÊNERO E MODOS DE SUBJETIVAÇÃO: INCURSÕES INVESTIGATIVAS EM UM PROGRAMA DE CAPACITAÇÃO
}

\author{
Daniele Vasco SANTOS ${ }^{1}$ \\ Secretaria de Estado de Saúde Pública do Pará \\ danielevasco@yahoo.com.br \\ Josenilda Maria Maués da SILVA ${ }^{2}$ \\ Instituto de Ciências da Educação/UFPA \\ jomaues@ufpa.br
}

Resumo: Este artigo resulta de uma pesquisa que examinou os modos de subjetivação colocados em funcionamento no currículo de um programa de capacitação em gênero e políticas públicas proposto por uma organização não governamental. Adotando como referencial teórico os estudos do campo do currículo e das relações de gênero produzidos por autores inspirados em grande medida na obra de Michel Foucault, a noção de currículo é assumida como prática discursiva atravessada por relações de poder-saber e envolvida em processos de subjetivação que intencionam transformar indivíduos em sujeitos, privilegiando a dimensão das relações de gênero. A análise de modos de subjetivação em funcionamento no currículo do programa de capacitação é efetuada tendo como fonte os documentos que subsidiam suas práticas pedagógicas. Como resultado, evidencia-se o caráter produtivo do currículo investigado ao colocar em funcionamento modos de subjetivação como investimento de estratégias de governo, que sinalizam como devem ser as relações de gênero e em que sentido os indivíduos precisam transformar-se para que estas relações sejam alcançadas.

Palavras-chave: Currículo. Gênero. Modos de Subjetivação.

Abstract: This article results on a research that has checked the ways of subjectivation worked on the curriculum of a capacitating program in gender and

\footnotetext{
${ }^{1}$ Psicóloga; Mestre em Educação/UFPA. Psicóloga da Secretaria de Estado de Saúde Pública do Pará - Coordenação Estadual de Saúde Mental, Álcool e Outras Drogas.

${ }^{2}$ Pedagoga/UFPA. Mestre em Educação/PUC-SP. Doutora em Educação/PUC-SP. Professora Adjunta da UFPA. Professora no Programa de Pós-Graduação em Educação da UFPA.
} 
public policies proposed by a non governmental organization. Using as theoretical reference the field studies of the curriculum and of the gender relations produced by authors the notion of curriculum is assumed as discursive crossed with canknow relations and involved subjectivation processes that intend to transform a person in subjects privileging the dimension of the gender relations. The analysis of the ways of subectivation working in the capacitating program is made as a source the documents that subsidize its education practices. As a result, we can see the productive side of the investigated curriculum putting on work ways of subjectivation such as investments on government strategies that shows how this gender relations must be and in what way this people need to change themselves to reach these relations.

Keywords: Curriculum. Gender. Modes of Subjectivation.

\section{Situando a pesquisa}

Este artigo resulta de uma pesquisa que examinou os modos de subjetivação colocados em funcionamento no currículo de um programa de capacitação em gênero e políticas públicas proposto por uma organização não governamental. Trata-se de uma investigação que se baseou nas formulações de Michel Foucault ${ }^{3}$, nas quais os modos de subjetivação se referem aos processos que transformam indivíduos em sujeitos $^{4}$ a partir das relações de saber-poder.

Foram analisadas as cartilhas produzidas pelo Programa de Capacitação de Multiplicadores (as) em Gênero e Políticas Públicas, propostas pela Federação de Órgãos para Assistência Sócio-Educacional

${ }^{3}$ Foram exploradas, basicamente, as seguintes obras de Michel Foucault: O sujeito e o poder (1995), Microfísica do poder (1998), Em defesa da sociedade (1999), A Ordem do discurso (2002), Arqueologia do saber (2004), O nascimento da biopolítica (2008), Vigiar e punir (2008).

${ }^{4}$ Como argumenta Fonseca (2003), os processos de objetivação e subjetivação referem-se sempre a indivíduos e o termo sujeito "expressará o resultado da constituição do indivíduo ante os mecanismos de subjetivação presentes na atualidade” (p. 26). 
$(\mathrm{FASE})^{5}$, como dispositivos ${ }^{6}$ pedagógicos que se preocupam com as mudanças nas relações de gênero, enunciando como estas relações podem/devem ser.

Além das mencionadas formulações foucaultianas, o trabalho estabeleceu interlocução com produções de teóricos como Tomaz Tadeu da Silva (2004, 2006), Alfredo Veiga-Neto (2004), Jorge Larrosa (2004), que permitiram problematizar o currículo como um processo constitutivo, produtivo, que fabrica e institui tanto os objetos dos quais fala, quanto os sujeitos aos quais se dirige. E no campo da discussão das relações de gênero, a pesquisa tomou como ponto de partida as condições que possibilitaram a emergência da noção de gênero, em suas vinculações políticas e linguísticas com os movimentos feministas contemporâneos, ressaltando o momento histórico de seu aparecimento no âmbito do debate teórico e suas reverberações enquanto preocupações sociais e políticas, tendo como referências teóricas as produções de Guacira Lopes Louro $(2001,2004,2006)$, Donna Haraway $(2004,1994)$ e Judith Butler (2003, 2007).

A preocupação com os modos de subjetivação colocados em funcionamento nas cartilhas do Programa de Capacitação fundamentouse na busca de questionamentos que subvertam formas de pensar o currículo, conhecimento, poder, tradicionalmente postos em um campo normalizador, que funciona permanentemente a partir de agendas programáticas e planos previamente preparados (LOURO, 2001).

No que se refere às relações de gênero, na medida em que educadores, currículos, escolas, enfim, todos os envolvidos com o campo educacional se vêem perplexos com questões para as quais saídas seguras já se encontram fechadas, com "novas" práticas e "novos" sujeitos sendo

\footnotetext{
${ }^{5}$ A FASE é a organização não governamental atuante no Estado do Pará mais antiga, de âmbito nacional, que articula recursos financeiros de entidades governamentais e não governamentais nacionais e internacionais, cuja missão é "contribuir para a construção de uma sociedade democrática através de uma alternativa de desenvolvimento sustentável" (FASE, 2009).

${ }^{6}$ Dispositivos entendidos como, um conjunto decididamente heterogêneo que engloba discursos, instituições, organizações arquitetônicas, decisões regulamentares, leis, medidas administrativas, enunciados científicos, proposições filosóficas, morais, filantrópicas. Em suma, o dito e o não dito são elementos do dispositivo. O dispositivo é a rede que se pode estabelecer entre estes elementos (FOUCAULT, 1998, p. 244).
}

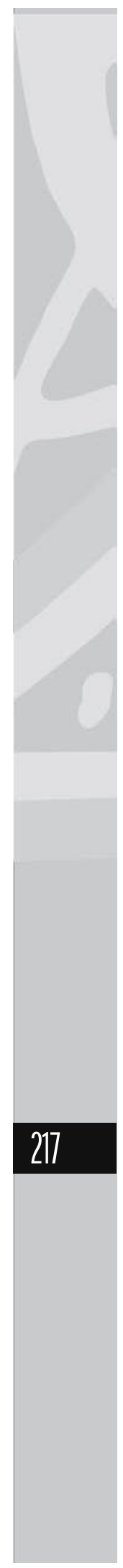


produzidos em termos globais, as questões postas como "problemas de gênero" são fundamentalmente importantes.

Para interrogar tais questões, a pesquisa operou a partir de uma noção de currículo na qual este não representa uma "coisa em si", em definições que capturam seu "verdadeiro significado". Longe de procurar desvendar algo "por trás" do currículo ou "essências" a ele atribuídas, compartilha-se a ênfase em seus efeitos produtivos, ampliando questões centrais formuladas a respeito dos conhecimentos a serem ensinados, sobre a validade dos saberes, e aliando-se às formulações acerca dos tipos de sujeito que se quer produzir (SILVA, 2006).

Tratou-se, nesse sentido, de entender as cartilhas como a materialização de um currículo que seleciona, privilegia e destaca o que devem ser as relações de gênero, em uma produção discursiva marcada pelas oposições e lutas sociais, como formas de manutenção ou modificação da apropriação de discursos atravessados por relações de saber-poder e que propõe modos de subjetivação.

Embora autores como Marcos Fonseca (2003), Veiga-Neto (2004) e Roberto Machado (2004) afirmem que não há uma definição com sentido único nas formulações foucaultianas para a expressão modos de subjetivação, no conjunto das pesquisas do filósofo, subjetivação é o processo pelo qual se obtém a constituição de um sujeito a partir de procedimentos e práticas que tendem a fazê-los objetos e que os fixam a uma identidade (VEIGANETO, 2004; FONSECA, 2003).

Se no ensaio "O Sujeito e o Poder" Foucault (1995) assinala que foi o sujeito a temática central de seus projetos, e não o poder, a problemática do sujeito fica bem mais entendida em suas últimas entrevistas e conferências, como "A ética do cuidado de si como prática da liberdade", de 1984, quando afirma que talvez tivesse feito formulações inadequadas - o que acabou sendo considerado por seus leitores e críticos como um "impedimento" ao falar sobre o sujeito -, mas sua recusa foi a da produção de uma teoria prévia do sujeito. Em suas palavras:

Procurei mostrar como o próprio sujeito se constituía, nessa ou naquela forma determinada, como sujeito louco ou são, como sujeito delinqüente ou não, através de um certo número de práticas que eram os jogos de verdade, práticas de poder etc. Era certamente necessário que eu recusasse uma certa teoria a priori do sujeito para poder fazer essa análise das relações 
possivelmente existentes entre a constituição do sujeito ou das diferentes formas de sujeito e os jogos de verdade, as práticas de poder etc. (FOUCAULT, 2006, p. 275).

Assim o sujeito, como tema geral de suas pesquisas, tomou formas diversas: sua objetivação como sujeito falante, realizada pelas investigações com estatuto da ciência, as práticas que dividem o sujeito no seu interior e, por fim, o estudo dos modos pelos quais um ser humano torna-se sujeito. E a retomada do sujeito, em seus últimos trabalhos, não implicava na construção de uma teoria do sujeito soberano, universal, como substância, mas na forma de problematizar sua constituição de jogos de verdade, práticas de poder (FOUCAULT, 2006).

Desse ponto de vista, é possível pensar os modos de subjetivação como um conjunto estruturado por uma racionalidade prática e governado por objetivos que transformam indivíduos em sujeitos de variados tipos, ligando-se a objetivos morais, políticos e sociais. E, no caso do currículo materializado nas cartilhas do Programa de Capacitação, pensá-lo como constituído por práticas cuja finalidade é agir sobre a ação dos indivíduos a que se referem, privilegiando a dimensão das relações de gênero e propondo que sejam de determinados tipos e ajam de determinadas formas, e interrogá-lo acerca do que se busca normatizar, quais transgressões permite efetuar/efetua.

\section{O Programa de Capacitação e os modos de subjetivação}

O Programa de Capacitação de Multiplicadores/as em Gênero e Políticas Públicas tem como público pessoas que atuam nos movimentos sociais e objetiva "formar multiplicadores na temática de gênero"; "discutir potencialidades para incorporação da dimensão de gênero em ações governamentais"; e "contribuir para a integração de sujeitos políticos no processo de incorporação de gênero em programas e políticas como elemento fundamental para uma maior equidade social" (FASE, 2001a).

Para contribuir no alcance desses objetivos, a FASE organizou a publicação "Gênero e Políticas Públicas", um conjunto de quatro

\footnotetext{
${ }^{7}$ Um conjunto de quatro cartilhas com a linguagem a partir dos quadrinhos, pontuada com algumas informações e definições, pois, "assim, as proposições críticas sobre as relações sociais desequilibradas entre homens e mulheres são mais fáceis de ser entendidas, e principalmente digeridas, por uma sociedade ainda desacostumada a reconhecer direitos iguais quando é recortada pela fronteira de gênero" (FASE, 2009).
}

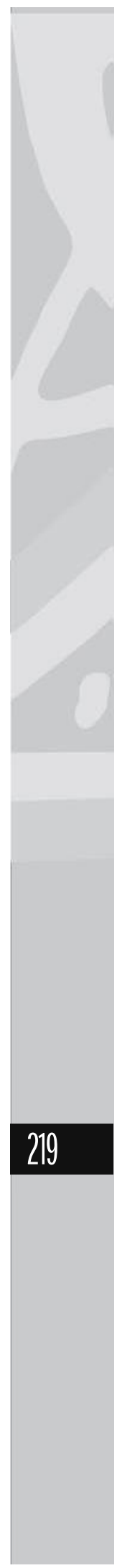


cartilhas. As cartilhas mantêm em comum um texto de apresentação, no qual os objetivos e proposta metodológica do Programa são apresentados, em sua divisão por módulos: “(1) A Formação do Conceito Gênero; 2) Gênero, Organização Social e Representação Política;3) Gênero e Políticas Públicas; 4) Planejamento e Metodologia de Trabalho com Gênero". Para cada módulo há uma cartilha que busca subsidiá-lo, intituladas: "Gênero e Sexo: Agora homem vai ter que usar saia?"; "Gênero e Poder: O tempo da política"; "Gênero e Políticas Públicas: Participando sem medo de ser mulher"; Gênero e Planejamento: construindo os caminhos da igualdade" (FASE, 2001a).

Erigidas em um feixe de relações - da articulação com outras organizações não governamentais nas práticas de "capacitação em gênero", dos financiamentos das agências internacionais para trabalho com mulheres aos diálogos com a literatura sobre gênero produzida na academia -, as cartilhas proferem enunciados ${ }^{8}$ referentes a um conjunto de domínios que objetivam discursivamente indivíduos para que suas experiências possam ser constituídas como sendo de sujeitos que lutarão por "uma sociedade mais justa do ponto de vista social, econômico e ambiental", questionando "posições de gênero" a partir de ações "transformadoras das formas de divisão de poder na sociedade" (FASE, 2001a, p. 30).

Como ponto de partida, as cartilhas elegem, como sujeitos que precisam ser transformados, mulheres que sofrem desigualdade na sociedade, no espaço da casa e do trabalho, e que não são "alvos" de políticas públicas, principalmente no que concerne aos aspectos produtivos (econômicos). São mulheres que no "espaço da casa" são responsáveis pelas tarefas domésticas, pelos cuidados com os filhos e marido (em uma relação na qual o homem detém o poder). No "espaço do trabalho" estas mulheres também estão em condição de subordinação em relação aos homens, recebem salários menores, são discriminadas, participam menos de cargos de chefia e processos decisórios. E, no "espaço das políticas públicas”, não têm atendimento integral à saúde, são vítimas de violência,

\footnotetext{
${ }^{8}$ Um enunciado estabelece uma relação diferenciada com sua proposição e com aquilo que enuncia. O que é posto em jogo é aquilo de que seu "tema" fala, não apenas o que é dito. Um enunciado não tem como correlato um indivíduo ou um objeto específico, singular, mas tão somente um conjunto de domínios onde os objetos emergem assinalando suas relações (FOUCAULT, 2004).
} 
não possuem crédito em agências de financiamento, apoio nos processos de cooperativismo e capacitação profissional, e não têm acesso às chapas eleitorais.

Para estas mulheres são direcionadas estratégias ${ }^{9}$ a fim de que sofram "transformações internas" e "se sintam com poder para lutar por mudanças" (FASE, 2001a, p. 28), em uma sociedade com "equidade de gênero". Estratégias colocadas em prática, fundamentalmente, a partir dos dispositivos de saber-poder usados pelos personagens das cartilhas que exercem a função de "lideranças comunitárias". Embora integrem a comunidade, por serem seus "representantes" e por apresentarem familiaridade com o espaço e seus moradores, esses personagens têm um diferencial que os habilita a serem "guias", a conduzir a conduta de outros, e este diferencial é apontado nos enunciados que proferem ao fazer denúncias, questionamentos, ao explicar conceitos e propor ações a partir dos regimes de verdade veiculados nas cartilhas.

Desse modo, as estratégias de transformação são colocadas em funcionamento, na narrativa das cartilhas, a partir de uma prática pedagógica em que todo e qualquer lugar/tempo serve como espaço formativo para que as lideranças comunitárias ensinem e as mulheres, que precisam ser transformadas, aprendam. Os "objetos" da aprendizagem são as relações de gênero e políticas públicas.

Para Larrosa (2004), as práticas pedagógicas são espaços de possibilidades para "desenvolver pessoas", onde a relação de quem aprende consigo mesmo é reelaborada a partir da consciência de fazer certas coisas consigo mesmo. Os lugares oferecidos partem das experiências "objetivas" do mundo e de experiências de mulheres como aquelas em que devem transformar-se para alcançar o horizonte da equidade de gênero.

Ressaltemos que as cartilhas elaboradas para o Programa de Capacitação constituem uma ação educativa da FASE para "apoiar, com uma visão própria, através de ações educativas e projetos demonstrativos, a constituição, o fortalecimento e a articulação de sujeitos coletivos de desenvolvimento" (FASE, 2009), tarefa central, portanto, para promoção

\footnotetext{
${ }^{9}$ Estratégias aqui pensadas em termos de "certa manipulação das relações de força, de uma intervenção racional e organizada nestas relações de força, seja para desenvolvê-las em determinada direção, seja para bloqueá-las, para estabilizá-las, utilizá-las” (FOUCAULT, 1997, p. 216).
}

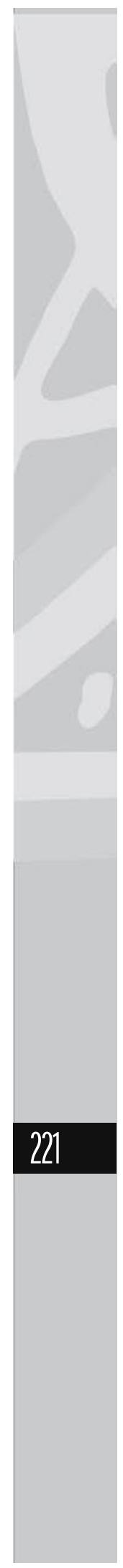


de processos de subjetivação, tendo como campo discursivo correlativo a chamada educação popular ${ }^{10}$.

Com a missão de gerar "sujeitos críticos por meio de ações pedagógicas conscientizadoras", na pressuposição de que as populações "marginalizadas" necessitam da apropriação de um saber que modifique suas realidades, os discursos produzidos no campo da educação popular tomam por empréstimo os questionamentos formulados pelas pedagogias críticas para quem os indivíduos serão mais ou menos críticos e conscientes, "segundo sua maior ou menor adesão a determinadas leituras do mundo social e a projetos políticos específicos" (GARCIA, 2002, p. 21).

São discursos que lutam pela imposição do que é ser estudante, docente, crítico, ingênuo, alienado; prometendo, via "esclarecimento", a emancipação e libertação da opressão de classe. E se os profissionais da educação cumprem, no campo das "pedagogias críticas", a função de gerar "sujeitos críticos, conscientes e emancipados", oferecendo-lhes modos de ação baseados em normas, conselhos e regras, os educadores populares, que podemos identificar como os "guias", personagens das cartilhas, a eles se assemelham com a diferença de que os espaços formativos não dizem respeito à escola, à educação "formal" (GARCIA, 2002).

Sendo guias no exercício de orientar a conduta de outros, as lideranças comunitárias são educadores populares em sua função de colocar em movimento estratégias que transformem sujeitos por meio de seu acompanhamento, cuidados e esclarecimentos contínuos. Se, por um lado, exercem essa função devido ao fato de terem qualidades, serem "sujeitos transformados" ("conscientes", "empoderados", "engajado politicamente") e servirem de modelo, por outro, colocam tecnologias de saber-poder em funcionamento, pois também oferecem, em suas orientações, um conjunto de saberes professados que oportunizam a aprendizagem de uma relação do sujeito com ele mesmo, permitindo-lhe a autorreflexão, o autoconhecimento.

\footnotetext{
${ }^{10} \mathrm{Na}$ década de 1970, a educação popular começou a ser discutida, tendo seus programas e métodos sistematizados por autores como Carlos Rodrigues Brandão. A década de 1990 foi um período de revisão paradigmática para a educação popular, quando a função dos "agentes externos" passa a ser o "despertar o educando para suas condições concretas de vida em termos de pobreza e suas causas, de interesse de classe explorada e oprimida" (GONH, 2005, p. 02).
} 
Um dos elementos desse dispositivo de cunho pedagógico da cartilha é o "desvelamento da realidade". Partindo da enunciação do "nãosaber" das mulheres que serão transformadas, essa realidade precisa ser "desvelada" para que seja possível a construção de formas de enfrentamento das desigualdades de gênero. A realidade referida nas cartilhas é a social na qual vivem as mulheres, e esta precisa ser "desvelada" com base na compreensão de conceitos como sexo, gênero, poder, "empoderamento" e classe.

Para além dos espaços e momentos formativos no processo de "desvelamento da realidade", os guias também orientam para o exercício de participação. Os objetivos perfilados pelo Programa de Capacitação e os objetivos permanentes da FASE possibilitam analisar em que sentido a estratégia de participação modifica a relação dos sujeitos com eles mesmos e com o mundo: "integrar sujeitos políticos no processo de incorporação de gênero em programas e políticas públicas como elemento fundamental para uma maior equidade social" (FASE, 2009), contribuindo "para a construção de uma alternativa de desenvolvimento fundada na justiça social, na preservação do meio ambiente e na aplicação da cidadania" (FASE, 2009).

E, finalmente, para que a participação seja possível, é necessário que haja um planejamento que oriente as ações, sejam elas no Centro Comunitário, nos movimentos sociais, nas políticas públicas ou em casa. O planejamento serve como ferramenta "capaz de reunir informações necessárias e apresentar caminhos possíveis para desenvolver objetivos e metas que se deseja alcançar por meio de um processo participativo" (FASE, 2001d, p. 8). É um instrumento que serve para guiar ações e condutas, juntamente com o processo de "desvelamento da realidade" e do exercício de participação. De acordo com os enunciados das cartilhas, planejar implica a capacidade de prever e controlar situações, coisas, indivíduos e, à medida em que os sujeitos transformados adquirem essa capacidade, estarão qualificados para a participação.

O uso de tecnologias de saber-poder, como "desvelar a realidade", participar e planejar, tem como objetivo incidir sobre as mulheres, orientando e moldando suas condutas. Para isso, é preciso lançar mão de variados campos discursivos que se atravessam e justapõem, tendo em vista os conceitos que veiculam e as práticas sociais que legitimam, como 
as conquistas dos movimentos de mulheres, a fim de instituir seus regimes de verdade. Assim, as noções de sexo, gênero, poder, "empoderamento", classe, entre outras, são invocadas a partir de campos discursivos que passam por diversos domínios na disputa do dizer verdadeiro acerca dos sujeitos que se intenciona transformar.

E se o exercício do poder, como afirma Foucault (1995), configurase em um jogo de relações entre indivíduos ou grupos, no qual se inscreve o modo de ação de alguns sobre os outros, as qualidades das lideranças comunitárias possibilitam conduzir sujeitos para sua transformação no horizonte da equidade de gênero. Mas é preciso que esses sujeitos se deixem guiar e passem a verem-se, narrarem-se, pensarem-se como sujeitos que precisam passar por transformações e ainda lutarem para que outras se dêem na sociedade, no que tange às relações de gênero. $\mathrm{E}$, ao se deixarem guiar, esses sujeitos têm um campo de ação estruturado, no sentido de enfrentarem seus problemas e dificuldades cotidianas, possibilitando um feixe de respostas e efeitos em torno da produção de modos de subjetivação.

E eis que nas cartilhas as estratégias de transformação produzem a "mulher empoderada" que assume, sobretudo, uma posição crítica e consciente frente à sua realidade; assume seu poder nas negociações tanto nos espaços de casa, quanto no trabalho e no espaço público; a "mulher produtiva" que se engaja no horizonte da equidade de gênero, objetivando seu "empoderamento econômico", a partir da inserção no "mundo do trabalho"; e, finalmente, a "mulher politicamente engajada" que já não ocupa o lugar de quem enuncia um "não saber" e precisa ser guiada continuamente pelas lideranças comunitárias, ela é uma "participante ativa" que, entre outras coisas, contribui para a formulação de pauta de reivindicação de políticas públicas que respondam às necessidades específicas das mulheres.

Nesse sentido, as estratégias referem-se às relações de forças que intencionam a transformação não só dos personagens das cartilhas, dos participantes do Programa de Capacitação e dos possíveis leitores das cartilhas, mas pretendem alcançar a sociedade, nos remetendo às tecnologias regulamentadoras dirigidas à espécie, levando em conta a vida (no caso das cartilhas nos espaços eleitos para mudança nas relações de gênero: a casa, o trabalho e a política). 
São tecnologias biopolíticas ${ }^{11}$, referentes às mulheres como uma população, em seus fenômenos globais, constituídas como objetos discursivos passíveis de análises, observações e intervenções. E, na medida em que as cartilhas têm como público mulheres de determinados "tipos" e objetivam alcançar o conjunto da população - tanto diretamente em suas práticas educativas, quanto indiretamente, no campo da formulação e controle das políticas públicas -, evidenciam, não só no campo institucional da FASE, mas instâncias governamentais, agências internacionais de financiamentos e instituições de ensino, em uma multiplicidade de interesses morais, políticos e sociais, em um campo de luta no qual o dizer verdadeiro sobre gênero, mulheres, divisão social e sexual do trabalho, está em disputa e todo um campo de práticas não discursivas se abre a partir das justificativas, orientações e recomendações para a formulação de políticas cujos fins morais e econômicos se tornam cada vez mais complexos, paradoxais.

Sem negar as práticas discriminatórias, às quais são submetidas, as malhas de poder que buscam capturar seus corpos nas mais variadas formas de violência e também os avanços das ações governamentais e não governamentais no enfrentamento de tais práticas, é possível questionarmos a busca de normatização de alguns tipos de sujeitos, em prol da exclusão de outros.

Nas cartilhas, a noção de gênero funciona como tentativa de rejeição às diferenças entre homens e mulheres, quando postuladas como desigualdades, buscando instrumentalizar mulheres para o exercício do poder, a partir da argumentação de que se as relações entre homens e mulheres são construídas, podem ser mudadas, alteradas. Assim é que as mulheres são convidadas para a tarefa de emancipação, como reverberação de uns dos projetos dos movimentos feministas que reivindicaram a

\footnotetext{
${ }^{11}$ Tecnologias de poder regulamentadoras dirigidas ao corpo como espécie, à multiplicidade dos homens no conjunto de processos sobre a vida, objetivando intervir em fenômenos em sua globalidade para seu controle e gestão (FOUCAULT, 1999). A noção de biopolítica serviu na pesquisa de ferramenta analítica para compreensão da proposição dos tipos de sujeitos pelas cartilhas do Programa de Capacitação como sujeitos que transformarão a sociedade, a partir do controle e formulação políticas públicas, e da inserção no mercado de trabalho.
}

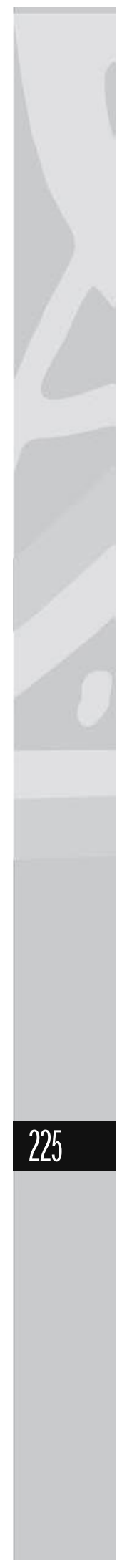


valorização dos atributos femininos e o reconhecimento no mundo público.

No entanto, em que pese o convite à emancipação das mulheres ser forjado a partir da argumentação que pretende sobrepujar concepções naturalizadas das diferenças entre homens e mulheres, ao fixar uma identidade para as mulheres com seus atributos e qualidades ("engajada", "consciente", "produtiva", etc.), é a categoria "mulher" invocada em sua condição de naturalização, por meio das categorias de sexo e gênero.

Para Butler (2003), a categoria "mulher", comosujeito do feminismo, acaba sendo produzida pelas mesmas estruturas de poder das quais se busca emancipá-la, ao tentar representar sujeitos que atendam às suas qualificações. Trata-se de compreender a categoria como uma formação discursiva e efeito de um sistema que produz sujeitos "generificados", quando predefine traços de gênero, tornando-se impossível separar a noção de processos políticos e culturais.

O argumento que alicerça as críticas da autora é de que a categoria "mulher" alcança estabilidade no contexto de uma matriz heterossexual, excluindo sujeitos que não se conformam às suas exigências normativas. E se a categoria permite a construção, no interior do feminismo, de uma unidade identitária, introduz, ao mesmo tempo, uma cisão dessa unidade por meio da relação sexo/gênero.

Ao postular um sujeito universal, resultante da opressão das mulheres, a autora afirma que os objetivos do feminismo correm o risco de fracassar ao aprisionar modos de ser em categorias que acabam por se naturalizar, reportando-se também às teorias totalizantes. Essa crítica não refuta uma política representacional, mas formula "uma critica às categorias de identidade que as estruturas jurídicas contemporâneas engendram, naturalizam e imobilizam" (BUTLER, 2003, p. 22), pretendendo libertar a teoria feminista de sua necessidade de construir uma base única.

Base única constituída a partir de processos de subjetivação que intencionam alterar as supostas identidades das mulheres, em favor de uma "sociedade com equidade de gênero". Em prol desta sociedade, as denúncias e questionamentos veiculados nas cartilhas constituem mulheres que precisam passar por processos de transformação, uma vez que o modelo de construção social enunciado nas cartilhas pressupõe que assim como "ela é", "ela pode (e deve) mudar". 


\section{Algumas considerações}

Interrogar as cartilhas do Programa de Capacitação implicou considerar uma concepção de currículo cuja materialidade não é apenas compreendida como transmissora de conhecimentos objetivos do mundo e que, embora não tenha parâmetros e diretrizes formulados pelos órgãos educacionais estatais, norteando os conhecimentos que devem ser ensinados, estes são selecionados, constituídos, por meio da articulação de elementos heterogêneos que se atravessam, se justapõem e por vezes se excluem.

A partir de tais interrogações, o lugar de quase-evidência das cartilhas foi analisado no sentido de recusar a proposição de tipos de sujeitos - como as mulheres "produtivas", "engajadas politicamente" e "empoderadas" - constituídos a partir de campos discursivos marcados por binarismos, noção de poder hierárquico e pelo imperativo da heteronormatividade, que pouco deixam espaço para subversão das formas de pensar as relações entre "gêneros", a produção de conhecimento e as relações de poder.

\section{REFERÊNCIAS}

BUTLER, J. Problemas de Gênero: feminismo e subversão da identidade. Rio de Janeiro: Editora Civilização Brasileira, 2003.

. Corpos que pesam: sobre os limites discursivos do "sexo". In: LOURO, G. L. (Org.). O Corpo Educado: pedagogias da sexualidade. Belo Horizonte: Autêntica, 2007.

FASE. Gênero e Sexo: agora homem vai ter que usar saia? Belém, 2001a. 30p. il.

Gênero e Poder: o tempo da política. Belém, 2001b. 30p. il.

Gênero e Políticas Públicas: participando sem medo de ser mulher. Belém, 2001c. 30p. il. 107

Gênero e Planejamento: construindo os caminhos da igualdade. Belém, 2001d. 30p. il. $\overline{\mathrm{jan} / 2009}$.

Disponível em: < http://www.fase.org.br/ > Acesso em: 05/ 
FONSECA, M. Michel Foucault e a Constituição do Sujeito. São Paulo: EDUC, 2003.

. O sujeito e o poder. In: DREYFUS, H; RABINOW, P. Michel Foucault, uma trajetória filosófica: para além do estruturalismo e da hermenêutica. Rio de janeiro: Forense, 1995.

FOUCAULT, M. Resumo dos Cursos do Collège de France. Rio de Janeiro: Jorge Zahar Ed., 1997.

Microfísica do Poder. Rio de Janeiro: Graal, 1998.

. Em Defesa da Sociedade: curso no Collège de France (1975/1976). São Paulo: Martins Fontes, 1999.

A Ordem do Discurso. São Paulo: Loyola, 2002.

. A Arqueologia do Saber. $7^{a}$ Ed. Rio de Janeiro: Forense Universitária, 2004.

Ética, sexualidade, política. $2^{\mathrm{a}}$ Ed. Rio de Janeiro: Forense Universitária, 2006. 2008a.

O Nascimento da Biopolítica. São Paulo: Martins Fontes, Vozes, 2008b.

Vigiar e Punir: nascimento da prisão. $35^{\mathrm{a}}$ Ed. Petrópolis:

GARCIA, M. Pedagogias Críticas e Subjetivação: uma perspectiva foucaultiana. Petrópolis: Vozes, 2002.

GOHN, G. (Org.). Movimentos Sociais e Educação. São Paulo: Cortez, 2005.

HARAWAY, D. "Gênero" para um dicionário marxista: a política sexual de uma palavra. In: Cadernos Pagu, v. 22, 2004. p. 201-246 Um manifesto para os cyborgs: ciência, tecnologia e feminismo socialista na década de 80. In: HOLLANDA, H. B. (Org.). O Feminismo como Crítica da Cultura. Rio de Janeiro: Rocco, 1994.

LARROSA, J. Tecnologias do EU e Educação. In: SILVA, T. T. (Org.). O Sujeito da Educação: estudos foucaultianos. $5^{\text {a }}$ Ed. Rio de Janeiro: Vozes, 2004.

LOURO, L. G. Teoria queer: uma política pós-identitária para a educação.

Revista Feminista. Florianópolis, v. 9 n. 2, 2001. 
Gênero, Sexualidade e Educação: uma perspectiva pósestruturalista. $7^{\mathrm{a}}$ Ed. Petrópolis: Vozes, 2004.

Gênero, Sexualidade e Educação: das afinidades políticas às tensões teórico-metodológicas. [anais] Caxambu: ANPED, 2006. 1 CDROM.

MACHADO, R. Foucault, a Ciência e o Saber. Rio de Janeiro: Jorge Zahar Ed., 2006.

PETERS, M. Pós-estruturalismo e Filosofia da Diferença. Belo Horizonte: Autêntica, 2000.

SILVA, T.T. Documentos de Identidade: uma introdução às teorias do currículo. $2^{\mathrm{a}}$ Ed. Belo Horizonte: Autêntica, 2004.

O Currículo como Fetiche: a poética e a política do texto curricular. Belo Horizonte: Autêntica, 2006.

VEIGA-NETO, A. Foucault e a Educação. $2^{\mathrm{a}}$ Ed. Belo Horizonte: Autêntica, 2004. 